alcohol into the muscles, an abundant development of mesenchymatous tissue is obtained around the muscle fibres more or less degenerated by the action af the alcohol. At the same time, one gets a plentiful regeneration of muscular tissue. On a closer examina. tion of these pictures, it is seen without difficulty that the newly developed muscles not infrequently grow in such a way that they cannot be imagined as having grown from old, pre-existing muscle fibres; but like the transplantation tests, must have developed directly from a mesenchymatous source (Fig. 2). I have furthermore tested the uterine mucous membrane (endometrium) ${ }^{8}$. It is well known in medicine how the uterine mucous membrane is found also outside the uterus, preferably around ovaries and oviducts, but also anywhere within the abdomenso-called endometriosis. Endometriosis has also been encountered in the muscles of the extremities. These findings are, of course, in favour of endometriosis being caused rather by a substance which activates mesenchymatous tissue than by dissemination of dis. rupted cell units. Transplantation tests with the endometrium, like those with bone and muscle, also support this conception (Fig. 3). In all these transplantation tests, I have never found any mitotic developments likely to explain the specific new developments.

The circumstance that a tissue is able to affect another in a specifically differentiating direction I have termed 'induction' $\longrightarrow$ a term borrowed from embryology, introduced, as is well known, by Spemainn and his school at the turn of the century. In embryology one speaks about an organizer or a system of action that induces, and a reacting system which is being induced. According to Spemann, induction takes place by way of chemical substances. The opinion is held that the induction ceases at the moment the development of the embryo ceases. The investigations referred to above show, however, that such is not the case. In the fully developed organism, too, a specific differentiation may take place inductively at all ages. The similarity between the embryonal reactions and, by way of example, the implantation tests during the postfoetal existence is clear. The graft in the fully de. veloped organism corresponds to the embryonal organizer or activator, and the newly developed mesenchymal tissue at the place of implantation, which can be influenced by the graft in a differentiating direction, to the embryonal reactionary system. The post-fotal presence of the induction mechanism thus means from the point of view of principle that the fully developed tissue comprises at least two components-a specific and an unspecific factor. Extraction tests with bone tissue show that the specific factor can be released from the tissue and dissolved in certain extraction fluids. This supportis the view that the specificity of the tissue is confined to certain chemical substances. If in tissue regeneration we find that the unspecific mesenchymal tissue is developed in different directions, we must assume that these chemical substances are able to activate the unspecific mesenchymblast into specific differentiation. Also in embryology there prevails, as is well known, the idea that the induction is transmitted by certain substances, and a vast amount of work has been devoted to attempts to isolate these substances. No definite results appear, however, to have been reached for the present. According to Needham and Waddington, these substances would seem to belong to the steroid group. Annersten has obtained active extracts with fat-dissolving extraction agents. Since it seems that the same mechanism is active within both the foetus and the fully developed organism as regards the explanation of growth, we are able to get a more comprehensive view of the development of tissues. There is every reason to assume that the same chemical substances are active both during the embryonal differentiation and during post-foetal growth. Regeneration of tissue is, in other words, a repetition of embryonal development.

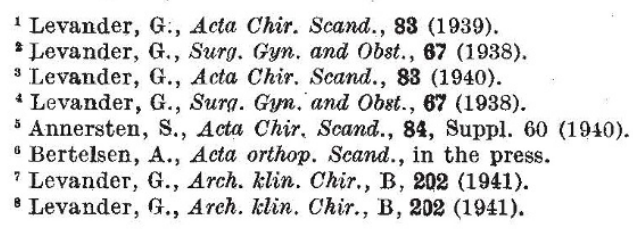

\section{TUNGSHAN OCEANOGRAPHICAL SURVEY IN 1941}

\author{
By DR. S. F. TANG \\ Department of Oceanograpny, China Institute of \\ Geography, Pei-Peh, Szechuan
}

A FIVE-YEAR plan for oceanographical survey along the ooast of Fukien was laid down in 1941 by the Department of Oceanography, China Institute of Geography, Pei-Peh, Szechuan, in cooperation with the Weather Bureau of Fukien, Yungan, Fukien. The purpose of such a survey is to give a complete picture, with the help of scientific knowledge, of coastal waters off Fukien. This investigation is expected to be a great help in the development of agriculture and fisheries. It may also be of benefit to the Salt Administration.

According to the plan, work has to be done systematically from south to north, along the coast, and this was started from Tungshan Island from 1941 onwards. The Tungshan Survey was made from the middle of September to the end of December 1941 by the Department of Oceanography in co-operation with the Weather Bureau of Fukien.

Workers engaged in the last survey were: Dr. S. F. Tang (oceanography and fisheries), Dr. T. Y. Ma (geology), Mr. Y. Chen (geography), Mr. K. M. Lin (physics), and Messrs. T. M. Chen and T. T. Young (meteorology). The first three were from the China Institute of Geography, Mr. Lin from the Research Academy of Fukien, Yungan, and the last two from the Weather Bureau of Fukien.

During the survey, observations on temperature, colour, transparency and specific gravity of the seawater at each station were taken continuously for a period of twelve hours. Tides and currents at each point were carefully measured. Readings were taken every five minutes for a period of more than a day for the tide, and every half an hour for half a day for the current. Specimens of corals, shells, sea animals and seaweeds were comprehensively collected and preserved, and meteorological data were simultaneously taken. This work has been continued by the observatory station which was then established in Tungshan city.

Tungshan Island is situated in lat. $23^{\circ} 32^{\prime}-45^{\prime} \mathrm{N}$. and long. $117^{\circ} 20^{\prime}-32^{\prime} \mathrm{E}$. and lies off the border 
between Kwangtumg and Fukien Provinces. Its length from north to south is twenty-two miles, and its width from east to west is eighteen miles; a channel separates the northern part of the island from the mainland and connects Tungshan Harbour on the east with Chaoan Bay on the west. Tungshan Harbour is a fishery port, and Chaoan Bay is of importance for its saltworks. Fishing and saltmaking enrich the islanders much more than the rice fields do the farmers on the mainland, though the lack of fresh water deprives the islanders of farming. As the results of warfare at sea, off-shore fisheries have practically disappeared. On the other hand, salt manufacture, because of the encouragement given by the Central Government and the increase of salterns and labourers, has been tremendously developed during the last five years.

It is to be noted that Tungshan is an important fishery centre in Fukien Province, and Tungshan Harbour is a very useful port along the south-west coast of China. Both as biologists and fishery investigators; we want to know the natural conditions of the fauna and flora in Tungshan waters, since these will give precise knowledge as to the position of the intermediate zone, biologically speaking, between the tropical and the temperate seas. From the practical point of view, such general biological knowledge will lead us to more accurate conclusions as to fish migrations.

Tungshan Harbour is mid-way along the AmoySwatow sea route, and affords merchantmen and fishing vessels a very convenient shelter during the typhoon season. However, the nature of the tides and currents in Tungshan Harbour is not yet known, as the necessary observations have not been made:

Several papers have been published upon the last survey, both at Chungking and at Yungan, by the China Institute of Geography. I have prepared two papers: "The Tides and Currents around Tungshan Island" and "The Semi-daily Variations of Salinity in Tungshan Waters".

In the first of these, I have shown that the tides and currents around Tungshan Island are of the semi-diurnal type, and that the salinities of Tungshan waters are variable.

The second paper can be summarized as follows : 1. The salt-content of the waters around Tungshan Island, especially along the northern part, varies considerably in a day. The greatest range, from $23 \cdot 20$ to $31 \cdot 40 \%$, was recorded in the water of Tungshan Channel, and the periodicity of the variation was found to be semi-diurnal.

2. It appears that around Tungshan Island the variation of salinity follows exactly the movement of the tide; that is, when the tide rises and the current is inward, the salinity of the water increases ; when the tide recedes and the current is outward, the salinity of the water decreases.

3. The salinity of Tungshan waters was found to reach the highest point generally half an hour before high water, as the salt-water at the time of high tide has already been covered on the surface by a layer of brackish water which comes down from up-stream.

4. Considering the Tungshan waters as a whole, the highest salinity recorded was $33.03 \%$, the average was $28 \cdot 12 \%$, and the lowest was $21 \cdot 92 \%$. The difference of $5 \%$ between the highest and the average means that the water of high salinity may produce one-fifth more salt than that of the average salinity which is generally used by the salt-makers of Tungshan Island.
5. The best sea-water for filling up the reservoirs of the salterns around Tungshan Island can therefore only be obtained during the period from three hours to half an hour before high water ; and the best day for filling up is the day following the new and full moons in each month.

\section{ROLE OF ISOLATION IN THE DIFFERENTIATION OF PLANT SPECIES}

\author{
EY G. LEDYARD STEBBINS, JUN. \\ University of California, Berkeley, California
}

$\mathrm{T}$ HE differentiation or origin of species depends upon the development of discontinuities or gaps in the variation pattern of Nature. We recognize species not because of the amount of difference between their most divergent individuals, but because of their distinctness from each other, or the breadth of the gap between them. The formation of these gaps between species depends upon the development of some isolating mechanism. Many different kinds of isolating mechanisms are found in Nature. In order to understand the forces which direct evolution, we must solve two major problems. These are first, how isolating mechanisms develop and become established as barriers between species, and second, what relation they have to morphological divergence, or the "descent with modification" of Darwin.

As an aid to the solution of these two problems, evidence is produced from our knowledge of species and species hybrids in the higher plants to support the following five statements.

First, isolation of two groups of individuals by geographic barriers, even for very long periods of time, does not necessarily cause them to evolve into distinct species. Certain species of eastern North America have been isolated from their relatives in eastern Asia for millions of years, and yet the populations on the two continents have remained exactly like each other during these long ages. Second, if two species have become recognizably different as a result of long-continued geographic isolation, they do not necessarily become isolated by genetic barriers also. Some American species, such as the American sycamore (Platanus) (British plane) and the Catalpa, are different in appearance from their Asiatic relatives; but the hybrids between them have been found (by other workers) to be fully fertile. Third, genetic isolating mechanisms, such as cross-incompatibility and hybrid sterility, do not appear suddenly, but evolve slowly as do the visible differences between species. Many plant species, as typified in the genus Pceonia, are in hybridization experiments partly incompatible with each other or form partially sterile hybrids. Such species may be in the process of evolving barriers of interspecific sterility between each other. Fourth, genetic isolating mechanisms have been produced artificially and analysed in laboratory or field experiments, but most of these mechanisms produce their effect in one or two large steps, and are transmitted in a relatively simple Mendelian fashion. On the other hand, the isolating barriers between natural species arise through the accumulation of many small steps, and are transmitted in the progeny of partially sterile interspecific hybrids according to the multiple factor pattern of inheritance. Fifth, 